Article

\title{
Optimizing Bus Passenger Complaint Service through Big Data Analysis: Systematized Analysis for Improved Public Sector Management
}

\author{
Weng-Kun Liu ${ }^{1, *}$ and Chia-Chun Yen ${ }^{2}$ \\ 1 Department of International Business, Feng Chia University, Taichung 40724, Taiwan \\ 2 Ph.D. Program in Civil and Hydraulic Engineering, Feng Chia University, Taichung 40724, Taiwan; \\ p0100212@mail.fcu.edu.tw \\ * Correspondence: wkunliu@fcu.edu.tw; Tel.: +886-4-2451-7250 \\ Academic Editors: Tan Yigitcanlar and Marc A. Rosen \\ Received: 6 September 2016; Accepted: 8 December 2016; Published: 14 December 2016
}

\begin{abstract}
With the advances in industry and commerce, passengers have become more accepting of environmental sustainability issues; thus, more people now choose to travel by bus. Government administration constitutes an important part of bus transportation services as the government gives the right-of-way to transportation companies allowing them to provide services. When these services are of poor quality, passengers may lodge complaints. The increase in consumer awareness and developments in wireless communication technologies have made it possible for passengers to easily and immediately submit complaints about transportation companies to government institutions, which has brought drastic changes to the supply-demand chain comprised of the public sector, transportation companies, and passengers. This study proposed the use of big data analysis technology including systematized case assignment and data visualization to improve management processes in the public sector and optimize customer complaint services. Taichung City, Taiwan, was selected as the research area. There, the customer complaint management process in public sector was improved, effectively solving such issues as station-skipping, allowing the public sector to fully grasp the service level of transportation companies, improving the sustainability of bus operations, and supporting the sustainable development of the public sector-transportation company-passenger supply chain.
\end{abstract}

Keywords: customer complaint process improvement; customer complaint service; big data analysis

\section{Introduction}

With urbanization, commerce development, and the popularization of the Internet, sustainable development has become an objective for all cities in Taiwan. The extension of bus services can facilitate travel, reduce the amount of traffic jams, and lower carbon dioxide emissions caused crowds of small passenger cars. Therefore, public transport policies (e.g., bus services) are actively promoted in Taiwanese cities and counties to meet passengers' demands.

There are three major players in bus operations (Figure 1), namely, the public sector (suppliers), bus companies (manufacturers), and passengers (consumers). The public sector (suppliers) normally provides right-of-way licenses (source materials) to bus companies (manufacturers) and information about ratified right-of-way operations to passengers (consumers).

Bus companies (manufacturers) develop service content (e.g., accessible buses, step-entrance buses, energy saving and noiseless electric buses, novel bus stop signs, and convenient bus shelters) based on the right-of-way licenses (source materials) that conform with relevant regulations in order to provide services to passengers (consumers). 
Passengers (consumers) can select bus routes based on their needs. If during the ride passengers (consumers) are dissatisfied or have suggestions, they provide a feedback to the public sector.

After receiving feedback, the public sector requires bus companies to make improvements and develop plans and strategies according to passengers' suggestions in order to improve municipal transportation services.

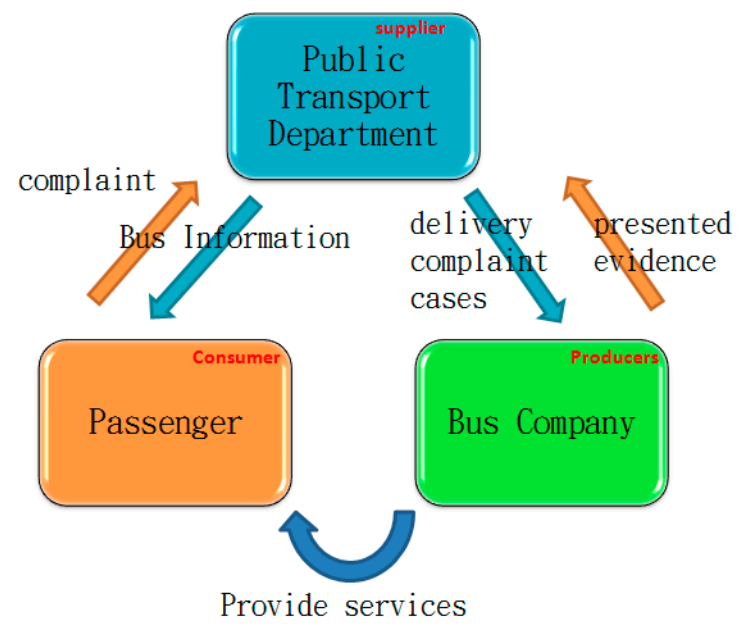

Figure 1. Customer service relations for public transportation services.

Bus transportation services are an important part of public services for which understanding passengers' feedback and meeting passengers' needs are important considerations. In other words, the government must pay more attention to passengers' opinions. Dealing with passengers' opinions is an unavoidable part of work in the public sector. The challenges and impacts for interactions between the public and private sectors due to these changes create new cooperative relationships between the government and the public; as a result, the concept of public governance is developed through public participation in decision-making. Under this concept, governing is no longer work exclusively done by the government but rather involves interaction between the government, companies, and non-profit (or non-governmental) organizations [1].

Understanding and analyzing each opinion and complaint can undoubtedly provide public managers insight into the possible preferences for specific issues, supplement the data regarding public opinion that was collected via traditional public participation channels (e.g., polls, forums, public hearings, seminars, and news media), and help with preparations and adjustments by perceiving potential social trends. Thus, an important role of passengers' extensive online involvement in public matters cannot be overlooked as it reflects passengers' participation and political behavior in the real world [2].

With regard to the supply chain relationship among the public sector, bus companies, and passengers, the rise of social autonomy brought on by the popularization of the Internet has resulted in changes in the social, political, and economic environments. Many government officials do not use the advantage of the Internet's interactivity and, instead, conceal many facts while considering public participation to be determined by individual power and that the Internet cannot be used to obtain large amounts of data in order to analyze problems, and assuming that all resources can be coordinated and supported by only the public sector; this reduces people's trust in the public sector [3].

Under such circumstances, online public opinion data have become available in large quantities, various formats, and at rapid speeds; these are the three Vs of digital data: volume, velocity, and variety. With regard to the public sector, the high-volume of online public opinion data brought by the spread of the Internet and networking facilities has provided democratic governments with an opportunity to gain insight into public opinions, which can help improve government responsiveness. However, 
due to its characteristics, big data presents a serious challenge for government departments and information systems in terms of data ingestion, analysis, management, and distribution [4].

As shown in Figure 2, as passengers become more accustomed to traveling by bus, their demands for the level of bus services increase. Passengers who are unsatisfied with bus services can express their opinion via multiple channels (e.g., the mayor's mailbox, department mailbox, 1999 Public Service Hotline, social networks, etc.). After receiving a passenger complaint, the case is classified, assigned to an audit employee to examine the deficiencies of the company and its services, and then a fine is imposed on the bus company according to the right-of-way agreement or traffic regulations.

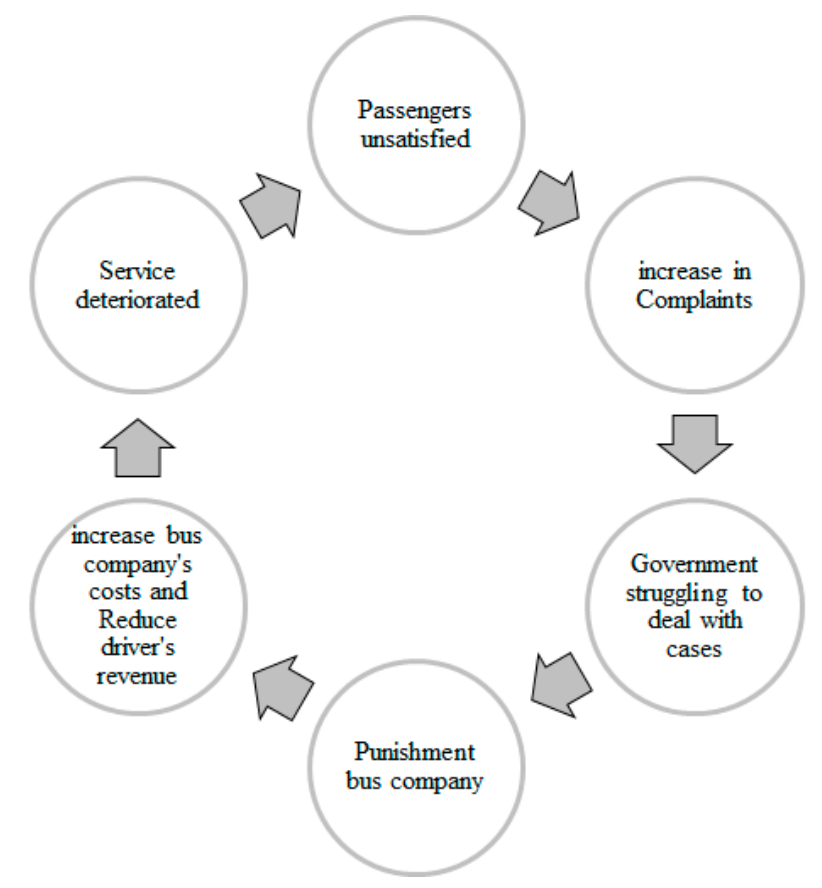

Figure 2. Vicious circle in the public sector-bus company-passenger supply chain.

Issues in the relationship among the public sector, companies, and passengers arise as passengers can now easily express their complaints and suggestions to the public sector over the telephone. A large amount of complaints creates a vicious circle in the supply chain relationship.

In order to break this vicious circle, this study suggested improving the existing customer complaint process done via paperwork. An improved management process in the public sector would allow it to accurately convey passenger complaints and suggestions to bus companies and instantly and effectively determine passenger needs. Effective management of complaints would improve the public transportation service environment.

This study examined the bus operations in Taichung City, Taiwan. Here, the public sector officially began using big data technologies to analyze complaints since April 2015 in order to systemically improve the customer complaint process. This study examined the customer complaints from April 2015 to February 2016. The statistical analysis of 11 months of data showed that it was possible to reduce the number of complaints for violations such as skipping stations, driving slowly, and unauthorized detours.

\section{Literature Review}

\subsection{The Importance of Bus Service Development}

City development and convenient transportation are inextricably connected. Industrial processes and methane emission in energy-involving activities such as transportation have amounted up to $60 \%$ 
of total emissions in Mexico; metropolitan and industrial waste accounted for $9 \%$ and agricultural, livestock, and land use changes and forestry accounted for $32 \%$. Trucks, buses, and compact cars accounted for 30\% of energy-related carbon dioxide emissions in Mexico. In Delhi, all 84,000 buses were renovated in the pursuit of the solution to this issue [5]. Thus, carbon reduction and ecological sustainable operations should be provided starting from public transportation services.

Therefore, the public transport system should be planned and designed appropriately and the use of private cars should be restricted. An important cornerstone of city development is the provision of road space and services sufficient for the vehicle population [6].

In Seoul, a reform of the public transport system was proposed that introduced Bus Rapid Transit (BRT) corridors which improved bus and subway coordination services and integrated fare and ticket booking systems and models. The reform was followed by an increase in customer satisfaction towards public transport safety, speed, and cost [7].

The popularization of public transportation services requires the government to use public power to implement reforms, create public agenda, and expand bus services [8]. Regardless of the country, the development of bus services is an important transportation policy for convenient transportation, energy conservation and carbon reduction, and ecological sustainability.

\subsection{Big Data Analysis}

Using an information and communication technology (ICT) model, the government developed a participatory website 1.0 (or Web1.0) into a participatory website 3.0 (or Web 3.0). The highly interactive Web 3.0 services have had an influence on the participation of the public in public matters in Taiwan and coincide with the OECD Web 3.0 model description [9]. In Taichung, with the popularization of $3 \mathrm{G}$ and $4 \mathrm{G}$ phones and the Internet, bus passengers can easily send a question about bus services to public sector via their smartphone or computer during the bus ride. The compilation of such data in large amounts is called big data.

When selecting a partner for the supply chain, private companies use the analytic hierarchy process and fuzzy synthetic evaluation to evaluate the big data indicators of each candidate, such as technology quality, big data processing capacity, credibility, financial situation, and service quality, in order to maintain relations with upstream and downstream supply chain companies [10].

\subsection{Customer Complaint Services}

Customer opinions and feedback can be conscious or unconscious, depending on whether the customer is aware of providing information to a third party. Implicit customer feedback is usually determined based on customers' consumption behavior (e.g., passengers' riding habits, consumption habits, etc.) [11-13].

Customer needs can be identified by searching for keywords in customer complaints [14] and the issues most concerning the customers can be determined based on the word frequency. The ARC (activities, resources, and context) framework integrates customer experiences and derives more opinions of customers through their interaction, thus, facilitating the development of text mining and enabling evaluation of the impact of customers' interactive service processes.

Private companies attach a high importance to customer feelings. In Taiwan, the government aims at providing services to the public and understanding people's needs. Therefore, starting from 25 January 2005, Taiwan has been implementing 1999 Public Service Hotline, the first-generation call center with 31 seats providing estimated 50,000 services per month. The public hotline provides all types of services, including appeal reports, administrative consultation services, road malfunctioning complaints, social welfare consultations, communications network consultations, and travel guide introductions.

Similar services were launched in Taichung City on July 2009, which the main function of answering people's questions regarding various polices. Provision of dial-in services with one easily remembered number simplified the previous use of a 0800 number (toll free number in Taiwan) for 
which the receiving side had to pay for the call and integrated phone lines from different institutions. The first five minutes of a call with the current 1999 hotline services (public hotline services) in Taichung are free. In addition, 1999 SMS services (public free short message services) are provided for the hearing impaired. The hotline attends to various non-urgent affairs in Taichung area, such as appeals, consultations, bus inquiries, bus service feedback, etc.

Table 1 presents the current situation of bus operations in Taichung City. A policy was implemented that provided free $10 \mathrm{~km}$ bus rides which has encouraged more passengers to travel by bus.

Table 1. Taichung City Bus Introduction.

\begin{tabular}{lll}
\hline Item & Content & Notes \\
\hline Range of bus operations & $\begin{array}{l}\text { Mainly Taichung City; several bus } \\
\text { routes reach Changhua County } \\
\text { and Nantou County }\end{array}$ & $\begin{array}{l}\text { Taichung City became a special municipality on } \\
\text { 25 December 2010 }\end{array}$ \\
\hline Taichung City population & $2,747,561$ & (as of February 2016) \\
\hline Taichung City area & Approximately 2215 sq. km & (as of March 2016) \\
\hline No. of bus companies in Taichung City & 14 & (excluding 7 sub-routes and 18 shuttle bus routes), \\
\hline No. of bus routes in Taichung City & 208 & (in September 2015) \\
\hline No. of bus passengers in Taichung City & $\begin{array}{l}\text { Average daily ridership: 366,000 } \\
\text { Monthly ridership: 10,980,000 }\end{array}$ & $\begin{array}{l}\text { The government provided subsidies to cover 10 km } \\
\text { fares and allow free ridership for passengers. }\end{array}$ \\
\hline $\begin{array}{l}\text { Fare system in Taichung City } \\
\text { No. of bus-related legal cases in }\end{array}$ & $\begin{array}{l}\text { Electronic card } \\
\text { No fare within 10 km }\end{array}$ & Approximately 1500 each month \\
\hline
\end{tabular}

Customer complaint data examined in this study was the original data obtained by the public sector from passengers by means of systematization, automated data collection, and data filtration. The data format included the document number, time of complaint, reason for complaint, and complaint content. One example of passenger complaints is provided in Table 2.

Table 2. One example of passenger complaints.

\begin{tabular}{|c|c|c|c|}
\hline Document No. & Complaint Time & Complaint Reason & Complaint Content \\
\hline 104-B48625 & $\begin{array}{c}14 \text { August } 2015 \\
11: 30\end{array}$ & $\begin{array}{l}\text { Report: } \\
\text { Station-skipping by } \\
\text { joint bus No. A }\end{array}$ & $\begin{array}{l}\text { Report: Mr. X reported that on } 13 \text { August at } 11: 20 \text { p.m., } \\
\text { bus No. A (Driver: Mr. Y; License Plate: B) in the direction } \\
\text { from Cheng Ching Hospital to Providence University, } \\
\text { used the fast lane to overtake the bus No. A that was in } \\
\text { front and had stopped at the bus stop. Blocked by bus } \\
\text { No. A, Mr. X could not wave his hand in time to signal } \\
\text { for bus No. A to stop. Mr. X reported that the bus did not } \\
\text { follow the regulations and skipped the station, suggesting } \\
\text { that the bus company improve training and asking for } \\
\text { assistance from relevant agencies. }\end{array}$ \\
\hline
\end{tabular}

Using the Taiwan government's interactive Web 3.0 and after many years of promotion and implementation, Taichung City bus passengers' awareness of their rights has increased, causing the number of complaint cases to grow. As a result, manual processing has become unable to provide prompt responses to all passengers and even caused many mistakes that brought about even more complaints. The service hotline is focused on improving citizens' quality of life while not giving enough consideration to the speed of processing and responding to questions [15] and, thus, reduces passengers' trust in the efficiency of the public sector. However, deficiencies in the complaint management process and low quality and speed of responding can greatly reduce passenger satisfaction with governmental services and create popular discontent. 


\subsection{Customer Complaint Process Improvement}

Traditionally, passenger complaints are managed manually. With technological development, in addition to traditional data collection channels, such as opinion polls, forums, public hearings, seminars, and news media, the government of every level also started using online forums, mayor's email, social media, and call centers. This resulted in prevalent participation of the public in public affairs via the Internet and easiness of expressing opinions. The use of ICTs by such an electronic government supported governmental operations, linked citizens and helped to provide governmental services. However, quick emergence of multiple and massive data related to public opinions in the Internet made it difficult for traditional data analysis and management processes to promptly respond to people's complaints [9].

The process of passenger complaint management generally includes five phases [16]. As shown in Figure 3 and described below, each phase has different outlines.

(1) Collection: If having a negative riding experience, public transportation passengers in Taichung City can report their opinions to the public sector by phone, social media, or email (Input). Unified collection of passenger opinions by the public sector (Process) assigns a document number (Output) to each passenger question.

(2) Classification: After the public sector receives passenger complaint cases (Input), official documents are issued for each complaint (Output) to be sent to relevant officials in charge (Process).

(3) Assignment: After receiving a complaint document (Input), the officials in charge verify the complaint, impose a fine on the bus company according to regulations, require the company to report improvement results (Process) and issue document notifying the bus company about the decision and fine and requiring an improvement report (Output).

(4) Improvement: After receiving the notification (Input), the bus company proposes improvement measures according to the document's content (Process) and sends documents providing improvement evidence back to the public sector (Output).

(5) Respond: Based on the bus company's improvement results, the public sector verifies the case again (Input) and assigns an official to report improvement results (Output) to the passenger by phone or email (Process).

The increase in the number of passengers presents challenges during four phases of the complaint management process in the public sector (Table 3) and causes the emergence of such issues as overdue, inaccurate classification, inefficiency of case assignment, and inefficient use of resources.

Table 3. Issues encountered by bus complaint management in Taichung City.

\begin{tabular}{cl}
\hline \multicolumn{1}{c}{ Phase } & \multicolumn{1}{c}{ Encountered Issue } \\
\hline Collection & $\begin{array}{l}\text { When processing a complaint case, public sector officials may have the case go overdue due to } \\
\text { the growing number of complaint cases and the absence of systemic control and management. }\end{array}$ \\
\hline Classification & $\begin{array}{l}\text { A growing number of passengers makes manual classification of cases inefficient. As the } \\
\text { number of cases increases, so does the classification error rate. }\end{array}$ \\
\hline Assignment & $\begin{array}{l}\text { A growing number of passenger complaints makes assignment of cases through paper } \\
\text { documents inefficient and may cause omissions. }\end{array}$ \\
\hline Improvement & $\begin{array}{l}\text { Under the circumstances of a growing number of passenger complaints, bus companies } \\
\text { find it difficult to determine main objectives for improvement and the efficiency of } \\
\text { resource use decreases. }\end{array}$ \\
\hline
\end{tabular}

This study proposed a method for business process improvement (BPI) to solve the existing issues through improvement of customer complaint process in public sector, management of each complaint case and question, and guidance and supervision over bus companies in the improvement of service quality. Improved service quality would naturally reduce passenger complaints and help achieve the objective of BPI. 


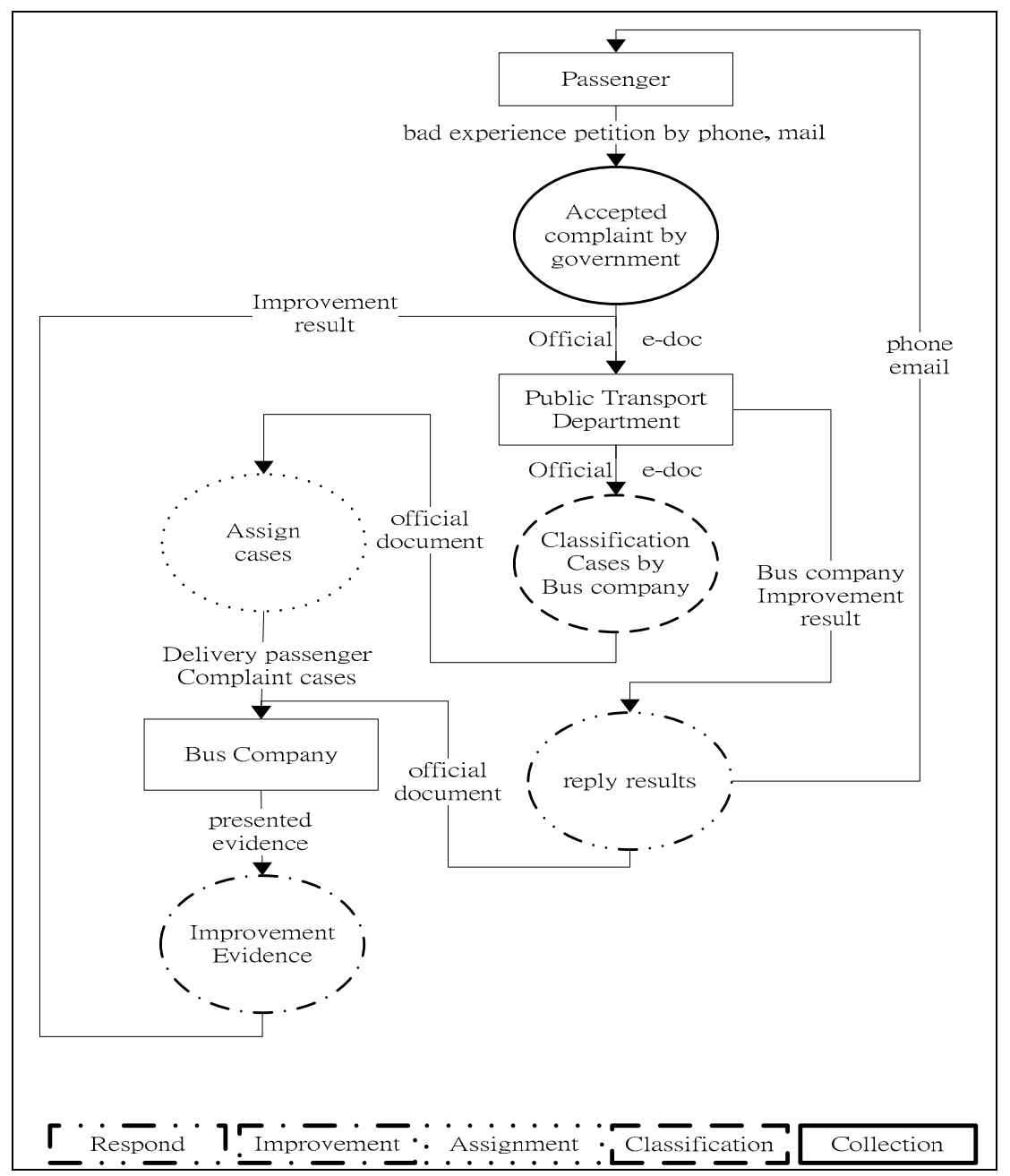

Figure 3. Five phases of the management process for bus passenger complaints in Taichung City.

\subsection{Business Process Improvement}

The company process is a set of logically related business activities. Each process involves the investment of such resources as people, materials, energy, equipment, and procedures and is aimed at creating a product or service for a final recipient [17].

BPI requires a wider outlook in IT and commercial activities. A company must have IT capability sufficient to support the company processes. However, many conditions need to be met by company for IT provision. IT is believed to be the most effective tool in reducing coordination costs [18]. Provision of unhindered and efficient processes in a new system allows prompter responses to situations and opportunities and fast receipt of valuable information, which facilitates implementation of policies and interaction with clients [19].

BPI is "a methodology that is designed to bring about step-function improvements in administrative and support processes using approaches such as process benchmarking, process redesign and process re-engineering" [20].

Businesses differ in terms of provided services. Desired performance can be reached by designing appropriate processes and improving designs in aspects that need to be strengthened [21]. Prior to implementing a plan, managers must have a good knowledge of current business processes in order to control the range of influence of the implemented plan and avoid or reduce negative consequences in case of failure [22]. 
For the purpose of BPI, a proper IT system is built using goals, rules, and methods. As such, it can effectively increase the efficiency of existing processes, as well as information updates and acquirement and establishment of communication channels, thus, reducing time costs and strengthening service performance [23]. Before the system establishment, ITs, human resources, and overall quality management related to the organization must be studied. These factors are correlated and cannot be taken into consideration separately. Changes are made possible through behavior and attitude training via communication between managers and workers, which shows the importance of effective communication and knowledge transfer [24].

\section{Research Methods}

In order to break the vicious circle of passenger complaint issues, this study analyzed the existing process of bus passenger complaint management and proposed improvement methods of each phase of the process. Moreover, statistical analysis was conducted for the complaint data collected during 11 months after actual implementation of the system in the public sector. Understanding of passenger complaint process improvements can help to reduce the amount of complaints and solve passengers' questions.

This study used big data technologies for systemic analysis of collection, classification, assignment, and improvement phases to improve the existing complaint process and provide the public sector with the direction for improving bus services, which would increase passenger satisfaction and reduce the amount of complaint cases. Improvements in each process phase are introduced below.

\subsection{Process Improvements in the Collection Phase}

In Taiwan, passengers can express their complaints about bus services at any time in any place. The unified public sector call center is available at 1999 (public free hotline and short message services in Taiwan) and has specialists who record passengers' opinions and ideas and add each complaint into the electronic document system. Each mail and phone record of passenger complaint is added to the electronic document system of the public sector and bus-related governmental institutions must respond and manage each suggestion and idea.

\subsubsection{Encountered Issues}

However, the number of passengers complaining about bus services is growing and so is the number of complaint cases that need to be managed by the public sector. Under the circumstances of the lack of systematized management and control, the public sector assigns an official to manage a complaint who is responsible for both receiving passenger complaints via 1999 calls and mail and re-directing them to the public sector. When an official needs to manage a complaint issue on site, the service may be overdue. Overdue receipt or omission of a passenger complaint affects passenger rights and causes more discontent among the public.

\subsubsection{Process Improvements}

To ensure that no complaint is omitted and increase efficiency of the on-site receipt of complaints, this study proposed to distinguish between complaint sources, such as 1999 and mail, and use a systematized method for recording complaints (Table 4). First, complaint cases are received via 1999 and mail using a systematized method. Then, complaint issues are assigned among free human resources. Finally, the chances of complaint case omission are reduced by adding an extra step of unified management and control. 
Table 4. Process improvements in the phase of collection.

\begin{tabular}{l} 
Process Improvement \\
\hline Process before the improvement:
\end{tabular}

Automatic receipt of passenger complaints with the use of a systematized method allows allocating surplus human resources to receive complaints on site in order to ensure systematization and absence of omitted complaint cases. Assignment of an extra manager for unified management and control in the phase of collection reduces the probability of complaint case omissions and allows to avoid overdue cases that are possible in the traditional manual complaint management.

\subsubsection{Process Improvement Outcomes}

Effectiveness of the improvement in the collection phase should be verified. Due to the systematized automatic receipt of complaints, the objective of the collection phase is to increase the speed of receiving complaints on site in order to reduce the amount of complaint cases in this phase and on hold. Thus, the decrease in $L$ and $L_{q}$ would indicate an improvement. Definitions of symbols used in the mathematical model are provided below:

$n$ is the amount of customers in the improvement phase;

$\lambda_{n}$ is the average arrival rate when there are $\mathrm{n}$ customers in the improvement phase;

$\lambda$ is the average arrival rate in the improvement phase $(1 / \lambda$ is the average interval between arrival times);

$\mu_{n}$ is the average service rate when there are $\mathrm{n}$ customers in the improvement phase;

$\mu$ is the service rate of one service provider $(1 / \mu$ is the average service time);

$\rho$ is the utilization ratio;

$L$ is the number of customers complain in the improvement phase; and

$L^{q}$ is the number of customers complain in the queue.

Currently, Taichung City customer complaints satisfy the following conditions:

- Non-fixed times of complaints are distributed according to a Poisson process.

- Service times are exponentially distributed.

- Bus passenger complaints are processed by the public sector on a first-come, first-served basis.

- The number of customer complaints is unlimited. 
Before the improvement in the collection phase, the public sector had a special service window for customer complaints, with exponentially distributed complaint receipt times (manual power). According to the queuing theory, the queuing model before the improvement was an $\mathrm{M} / \mathrm{M} / 1$ model.

$$
\begin{aligned}
& \rho=\frac{\lambda}{\mu} \\
& L=\sum_{n=0}^{\infty} n p^{n}=(1-\rho) \sum_{n=0}^{\infty} n \rho^{n}=(1-\rho) \rho \sum_{n=0}^{\infty} n \rho^{n-1}=(1-\rho) \rho \sum_{n=0}^{\infty} \frac{d}{d \rho} \rho^{n} \\
& =(1-\rho) \rho \frac{d}{d \rho} \sum_{n=0}^{\infty} \rho^{n}=(1-\rho) \rho \frac{d}{d \rho}\left[\frac{1}{1-\rho}\right]=(1-\rho) \rho \frac{1}{(1-\rho)^{2}}=\frac{\rho}{1-\rho}=\frac{\lambda}{\mu-\lambda} \\
& L_{q}=\sum_{n=1}^{\infty}(n-1) p_{n}=\sum_{n=1}^{\infty} n p_{n}-\sum_{n=1}^{\infty} p_{n}=L-\left(1-p_{0}\right)=\frac{\rho}{1-\rho}-\rho \\
& =\frac{\rho^{2}}{1-\rho}=\frac{\lambda^{2}}{\mu(\mu-\lambda)}
\end{aligned}
$$

After introducing the improvement into the collection phase, a worker responsible for control and management of the progress of complaint management was added to the existing complaint window, resulting in the availability of two windows for customer complaints. Complaint receipt times (manual power) were exponentially distributed. According to the queuing model, the queuing model was an $\mathrm{M} / \mathrm{M} / 2$ model.

$$
\begin{aligned}
& \rho=\frac{2 \lambda}{2 \mu+\lambda}=0.4 \\
& L=\frac{2 \rho}{1-\rho^{2}} \\
& L_{q}=\lambda\left[\frac{\rho^{2}}{\mu\left(1-\rho^{2}\right)}\right]=\frac{2 \rho^{3}}{1-\rho^{2}}
\end{aligned}
$$

Mathematical model calculation results:

Before the collection improvement in the public sector complaint process in Taichung City:

A. The public sector implemented one service window for collecting complaint cases.

B. The public sector had an 8-h workday with 21 work days per month. Passengers complaining about bus services to the public sector were exponentially distributed. On average, there were 1680 complaint cases per month and 10 cases could be processed per hour.

C. Complaint receipt times (manual power) were exponentially distributed, with the average complaint time of $5 \mathrm{~min}$.

$$
\begin{aligned}
& \lambda=10 / h \\
& \frac{1}{\mu}=5 \mathrm{~min}=\frac{1}{12} h \\
& \mu=12 / h \\
& \rho=\frac{\lambda}{\mu} \approx 0.83 \\
& L=5 \text { cases } \\
& L_{q}=\frac{100}{24} \approx 4.17 \text { cases }
\end{aligned}
$$

After the collection improvement in the public sector complaint process in Taichung City:

A. A worker responsible for control and management of the progress of complaint management was added to the existing complaint window, resulting in the availability of two windows for customer complaints.

B. The public sector had an 8-h workday with 21 work days per month. Passengers complaining about bus services to the public sector were exponentially distributed. On average, there were 1680 complaint cases per month and 10 cases could be processed per hour.

C. Automatic synchronization of complaint cases: automatic receipt of passenger complaints reduced the time of manual receipt of complaints. Complaint receipt times were exponentially distributed, with the average complaint time of $3 \mathrm{~min}$. 


$$
\begin{aligned}
& \lambda=10 / h \\
& \frac{1}{\mu}=3 \mathrm{~min}=\frac{1}{20} h \\
& \mu=20 / h \\
& \rho=\frac{2 \lambda}{2 \mu+\lambda}=0.4 \\
& L=\frac{2 \rho}{1-\rho^{2}} \approx 1 \text { cases } \\
& L_{q}=\lambda\left[\frac{\rho^{2}}{\mu\left(1-\rho^{2}\right)}\right]=\frac{2 \rho^{3}}{1-\rho^{2}} \approx 0.15 \text { cases }
\end{aligned}
$$

As verified by the mathematical model calculations, the improvements in the collection phase (Table 5) could reduce the idle time and the number of complaint cases queuing to be processed by public sector.

Table 5. Collection phase before and after the improvement.

\begin{tabular}{lcc}
\hline & $\begin{array}{c}\text { Collection Phase } \\
\text { before Improvement }\end{array}$ & $\begin{array}{c}\text { Collection Phase } \\
\text { after Improvement }\end{array}$ \\
\hline Number of customers complain in the system & 5 & 1 \\
\hline Number of customers complain in the queue & 4.17 & 0.15 \\
\hline
\end{tabular}

\subsection{Process Improvements in the Classification Phase}

After receiving complaint cases during the collection phase, public sector enters the classification phase, which generally involves officials classifying complaint cases based on a bus company.

\subsubsection{Encountered Issues}

The increase in the number of customer complaints causes inefficiency of manual classification of complaint cases and a growing error rate.

A large number of complaint cases cannot be effectively managed using the traditional manual method and assigned to an appropriate official, which is an important issue in the classification process.

\subsubsection{Process Improvements}

To solve the issue of big data classification and improve the existing manual procedure of complaint case classification, this study proposed using text mining technologies and keywords to classify customer complaint cases. Sullivan defined text mining as a process of editing, organizing, and analyzing big data to provide a specific user with specific information and determine features and the relationships between features [25]. Text mining is equivalent to data mining and uses a data selection processing program to extract complex features.

Text mining technologies were used to improve the classification phase [26]. First, personal data of complaining passengers and the data of corresponding public sector officials were filtered to facilitate further tracking of a complaint case. After data filtering of each complaint case, violations described in cases were classified using text mining, which increased complaint processing speed by public sector officials and reduced the error rate in case judgments.

\subsubsection{Case Match Rate Analysis}

By using a systematized method for filtering data and automatic classification of cases, a risk of misrepresenting data can be avoided and case processing time can be reduced.

Public sector keywords were used in the classification phase. Regular expression technologies were applied to derive a violation type from complaint data, which accelerated complaint management by public sector officials and reduced the error rate in their judgments. Thus, a higher match rate in a complaint case indicated a higher efficiency of public sector in processing the case. This study examined 3054 cases collected over two months. Match results were automatically produced by 
a cross-match system and interpreted manually. Manual approaches are applied to clearly check the result, four indexes have been developed as presented in Figure 4. The first index is that the matching is right, which means that the complaints text feature and the RE (Regular Expression) algorithm matched successfully. In addition, the matching result turned out to be right after comparing to the manual examination. The second is that the matching is wrong, obviously, because the RE algorithm matched some words but it turned out to be wrong after manual examination, Similarly, the other two are not matched and being wrong, and not matched but right, respectively, whose practical significance are easily understood.

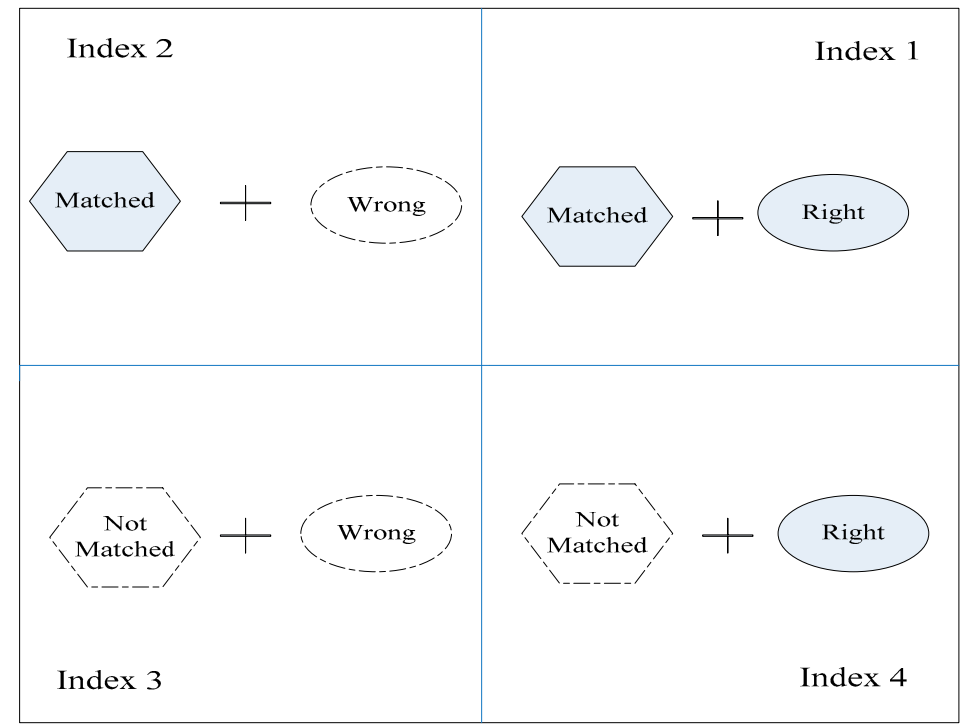

Figure 4. Four matching accuracy indexes.

The index's matching rates have been calculated and shown in Figure 5. The matching accuracy, which is defined as the sum of Index 1 and Index 4, was also calculated, as illustrated by the blue line. Seen from the figure, the license plate has achieved the highest accuracy, which is $100 \%$, followed by the violation state matching and the time matching, which are $97.87 \%$ and $97.09 \%$, respectively.

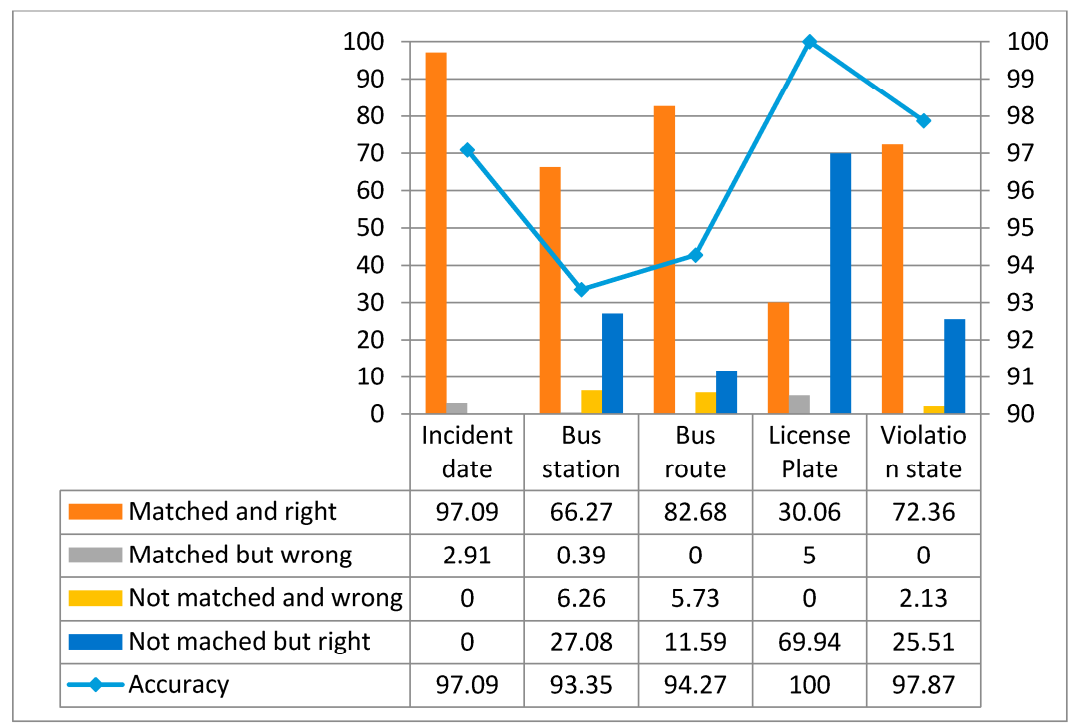

Figure 5. Accuracy after applying Text Mining Technologies. 


\subsection{Process Improvements in the Assignment Phase}

After classifying all complaints, public sector assigns each complaint case in the form of a paper document with a serial number to an official.

\subsubsection{Encountered Issues}

Traditionally, a complaint case is assigned in the form of a numbered paper document for processing by a public sector official. When the number of complaint cases is small, public sector officials have sufficient time to process the cases. The increase in the number of complaints reduces the efficiency of case assignment through paper documents.

\subsubsection{Process Improvements}

This study proposed improvement measures for the assignment process, specifically, the use of a systematized model in complaint case assignment. The assignment phase in this case must be preceded by automatic classification of complaint content (violation state, incident time, bus station, bus route, and license plate), based on which public sector can assign complaint cases to appropriate officials, thus, ensuring effective assignment of complaint cases.

Moreover, due to overall electronization of the assignment process after the improvements, public sector officials use the electronization method of the improved classification system to assign complaint cases to bus companies.

\subsubsection{Process Improvement Outcomes}

Different officials may have different efficiency in terms of complaint case management depending on the type of violation. In the assignment phase, all filed complaint cases should be assigned to or controlled by appropriate human resources to complete the case management within the planned period of time (E.T.). In the existing structure of complaint case management, manpower was assigned such that to reach balance in the production line. Definitions of symbols used in the mathematical model are provided below.

The model involves n workstations and one on one assignment issues.

$i$ is the number of workers available for assignment, $1 \sim n$.

$j$ is the number of workstations that need to be assigned, $1 \sim n$.

$T_{i j}$ is the time required for finishing work by a worker $i$ at a workstation $j$.

$X_{i j}$ is the used to control whether or not the element needs to be assigned.

Based on the definitions, this study developed a mathematical model with the following target and constraint formulas:

$$
\begin{gathered}
i=1,2, \ldots, n \\
j=1,2, \ldots, n \\
X_{i j} \in 0 \text { or } 1 \\
\text { s.t. } X_{11}+X_{12}+X_{13}+\ldots+X_{1 n}=1 \\
X_{21}+X_{22}+X_{23}+\ldots+X_{2 n}=1 \\
X_{31}+X_{32}+X_{33}+\ldots+X_{3 n}=1 \\
\ldots \\
\ldots \\
\ldots \\
X_{n 1}+X_{n 2}+X_{n 3}+\ldots+X_{n n}=1
\end{gathered}
$$




$$
\begin{gathered}
X_{11}+X_{21}+X_{31}+\ldots+X_{n 1}=1 \\
X_{12}+X_{22}+X_{32}+\ldots+X_{n 2}=1 \\
X_{13}+X_{23}+X_{33}+\ldots+X_{n 3}=1 \\
\ldots \\
\ldots \\
\ldots \\
X_{1 n}+X_{2 n}+X_{3 n}+\ldots+X_{n n}=1
\end{gathered}
$$

$X_{i j}=0$ is used to control a worker $i$ not assigned to a workstation $j$.

$X_{i j}=1$ is used to control a worker $i$ assigned to a workstation $j$.

$T_{i j} \times X_{i j}$ : if equal to 0 , indicates that a worker $i$ is not assigned to a workstation $j$; if not equal to 0 , indicates that a worker $i$ is definitely assigned to a workstation $j$; the value represents an actual output of the workstation.

D: Assuming that there are $m$ ways to classify compliant cases and due to the influence of classification accuracy on assignment accuracy, classification with the highest accuracy is used, $\mathrm{D}=\operatorname{Min}(\mathrm{D} 1, \mathrm{D} 2, \mathrm{D} 3, \ldots, \mathrm{Dm})$.

E.T.: Time that is expected to be spent on the management of a complaint case among all feasible solutions; E.T. before (B.E.T.) and after (A.E.T.) process improvements can be distinguished.

B.E.T.: Prior to the process improvements, complaint cases were assigned using a linear method. There was a $50 \%$ probability that complaint cases would be assigned to a non-appropriate official. In other words, there was a $50 \%$ probability of spending maximum time on case management and a $50 \%$ probability of spending minimum time on case management.

$$
\text { B.E.T. } \left.=\left(\underset{j=1}{n}\left\{T_{i j} \times X_{i j}\right\}\right) * 50 \%+\underset{j=1}{n}\left\{T_{i j} \times X_{i j}\right\}\right) * 50 \%
$$

A.E.T.: After the process improvements, classified complaint cases were assigned to those officials who could manage them most efficiently. Thus, the accuracy of classification affected time that was expected to be spent on case management after the improvements. The strictest classification accuracy can be used as a control variable to calculate time expected to be spent on case management.

$$
\text { A.E.T. }=\left(\underset{j=1}{n}\left\{T_{i j} \times X_{i j}\right\}\right) * D+\left(\underset{j=1}{n}\left\{T_{i j} \times X_{i j}\right\}\right) *(1-D)
$$

Mathematical model calculation results:

$i=$ three officials; and

$j=$ three types of violation in complaint cases, C1, C2, and C3.

Tables 6-9 present nine case management times differing among three officials and depending on three types of complaint cases.

Table 6. The processing time of three officials assigned to process three cases.

\begin{tabular}{cccc}
\hline & $\boldsymbol{i}=\mathbf{1}$ & $\boldsymbol{i}=\mathbf{2}$ & $\boldsymbol{i}=\mathbf{3}$ \\
\hline$j=1$ & $\mathrm{~T} 11: 2 \mathrm{HR}$ & $\mathrm{T} 21: 1 \mathrm{HR}$ & $\mathrm{T} 31: 3 \mathrm{HR}$ \\
$j=2$ & $\mathrm{~T} 12: 1 \mathrm{HR}$ & $\mathrm{T} 22: 3 \mathrm{HR}$ & $\mathrm{T} 32: 2 \mathrm{HR}$ \\
$j=3$ & $\mathrm{~T} 13: 3 \mathrm{HR}$ & $\mathrm{T} 23: 2 \mathrm{HR}$ & $\mathrm{T} 33: 1 \mathrm{HR}$ \\
\hline
\end{tabular}

If $X_{i j}$ is: 
Table 7. The maximum processing time of officials assigned to process three cases

\begin{tabular}{cccc}
\hline & $\boldsymbol{i = 1}$ & $\boldsymbol{i}=\mathbf{2}$ & $\boldsymbol{i = 3}$ \\
\hline$j=1$ & $\mathrm{X} 11: 0$ & $\mathrm{X} 21: 0$ & $\mathrm{X} 31: 1$ \\
$j=2$ & $\mathrm{X} 12: 0$ & $\mathrm{X} 22: 1$ & $\mathrm{X} 32: 0$ \\
$j=3$ & $\mathrm{X} 13: 1$ & $\mathrm{X} 23: 0$ & $\mathrm{X} 33: 0$ \\
\hline
\end{tabular}

then

$$
\underset{j=1}{n}\left\{T_{i j} \times X_{i j}\right\}=3 H R
$$

If $X_{i j}$ is:

Table 8. The minimum processing time of officials assigned to process three cases.

\begin{tabular}{cccc}
\hline & $\boldsymbol{i = 1}$ & $\boldsymbol{i}=\mathbf{2}$ & $\boldsymbol{i = 3}$ \\
\hline$j=1$ & $\mathrm{X} 11: 0$ & $\mathrm{X} 21: 1$ & $\mathrm{X} 31: 0$ \\
$j=2$ & $\mathrm{X} 12: 1$ & $\mathrm{X} 22: 0$ & $\mathrm{X} 32: 0$ \\
$j=3$ & $\mathrm{X} 13: 0$ & $\mathrm{X} 23: 0$ & $\mathrm{X} 33: 1$ \\
\hline
\end{tabular}

then

$$
\stackrel{n}{\operatorname{Min}}\left\{T_{i j} \times X_{i j}\right\}=1 H R
$$

Before process improvements:

$$
\text { B.E.T. }=(3 \mathrm{HR}+1 \mathrm{HR}) / 2=2 \mathrm{HR}
$$

After process improvements:

According to the match ratio of cases, $\mathrm{D}=\operatorname{Min}(97.09 \%, 93.35 \%, 94.27 \%, 100 \%, 97.87 \%)=93.35 \%$,

$$
\text { A.E.T. }=(1 \mathrm{HR} \times 0.9335+3 \mathrm{HR} \times(1-0.9335))=1.133 \mathrm{HR}
$$

Expected time of case management (E.T.) was reduced from $2 \mathrm{~h}$ before the process improvements to $1.133 \mathrm{~h}$ after the process improvements.

Table 9. The expected processing time before and after process improvements.

\begin{tabular}{ccc}
\hline & Before Process Improvements & After Process Improvements \\
\hline E.T. & $2 \mathrm{HR}$ & $1.133 \mathrm{HR}$ \\
\hline
\end{tabular}

\subsection{Process Improvements in the Improvement Phase}

Bus companies follow recommendations to improve their services and are supposed to provide public sector with a report about the improvements within a certain period of time.

\subsubsection{Encountered Issues}

The increase in the number of complaint cases keeps bus companies and public sector constantly on the run trying to solve all issues raised by passengers. Due to limited resources, some issues remain ignored, which indicates inefficiency and inability to meet passengers' needs.

\subsubsection{Process Improvements}

To facilitate decision-making in the public sector, this study added the application of big data analysis technologies in the improvement phase to include statistical case information into a geographic 
information system (GIS). Generally, a heat map is used for high-density point data. It can be applied to identify high-density areas in point data and is very useful in cluster analysis and hot spot analysis [27].

Application of a systematized method in the management of all complaint data regarding Taichung bus services allows to statistically derive hot spots of customer complaints based on the content related to incident time, incident place, and violation. These hot spots can then be presented in GIS, allowing public sector and bus companies to focus on improvements in these areas under the conditions of limited resources.

After improving services in hot spots, bus companies provide public sector with electronic evidence data and an official report document upon completion of several complaint cases.

\subsubsection{Process Improvement Outcomes}

Efficiently and transparently presented complaint hot spots allowed to identify city areas with the highest amounts of complaints represented by the most evident points. These areas included Taichung Railway Station (A), Yizhong Street (B), Feng Chia Night Market (C), and Mitsukoshi and Far Eastern Department Stores (D) (Figure 6). The complaint hot spots represented in the A and B areas are larger than those hot spots in the $\mathrm{C}$ and $\mathrm{D}$ areas. That is, the $\mathrm{A}$ and $\mathrm{B}$ areas have higher amounts of complaints in Taichung downtown. Governmental institutions can prioritize management decisions on the basis of this important information.

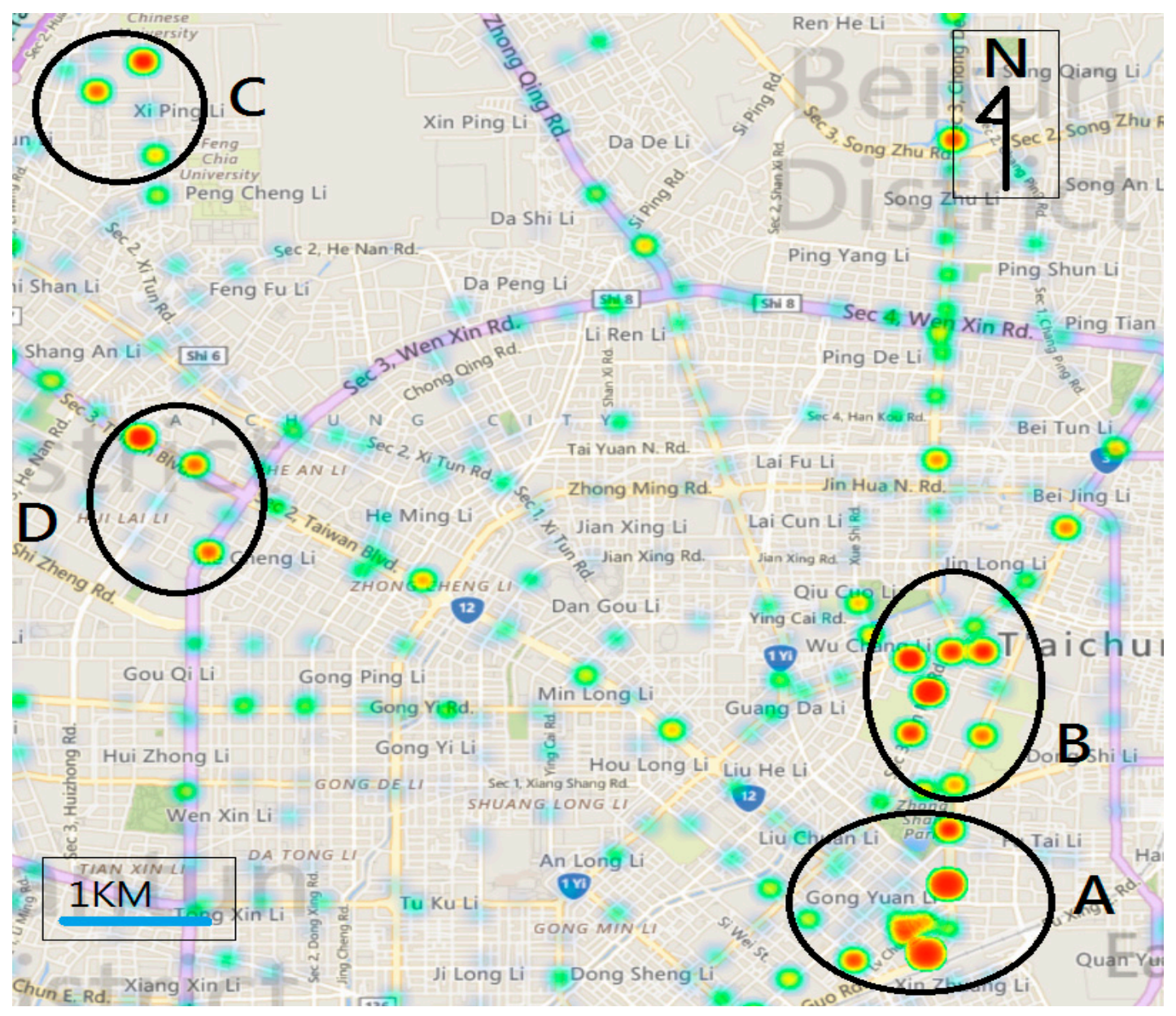

Figure 6. Heat map of passenger complaint in Taichung downtown.

\subsection{Summary}

This study proposed improvements for each phase of the bus passenger complaint process. 
In the collection phase, a systematized automatic approach was used to collect complaint data and unified control and management were added to the process. Mathematical model calculations showed that the process improvements could reduce the amount of pending cases in the system, as well as the waiting time of complainants.

In the classification and assignment phases, it was proposed to use text mining technologies for automatic data filtering, intelligent retrieval of complaint keywords, and compilation of complaint management samples based on the keywords. Automatically classified complaint cases were assessed for their type and assigned to officials who were more skilled in managing a certain type of complaints. This increased the efficiency of case management and reduced its time. Mathematical model calculations showed that the process improvements could reduce time required for case management.

In the improvement phase, text-mining data from the previous phase was analyzed for hot spots using big data analysis technologies and presented as GIS. This allowed public sector and bus companies to make improvements in passenger complaint hot spots and effectively solve most questions raised by passengers, while effectively using resources. Thus, the improvements could increase the effectiveness of using limited resources.

As shown in Table 10, after the improvements in the collection phase, the number of complaint cases in the system and in the queue was reduced from 5 to 1 and from 4.17 to 0.15 , respectively. In the classification and assignment phases, the use of text-mining technologies reduced time required for case management (E.T.) from 2 to $1.133 \mathrm{~h}$.

Table 10. Processes in each phase before and after improvements.

\begin{tabular}{|c|c|c|c|c|}
\hline \multirow{3}{*}{ Collection } & Improvement Objective & $\begin{array}{l}\text { Before process } \\
\text { Improvement }\end{array}$ & $\begin{array}{l}\text { After process } \\
\text { Improvement }\end{array}$ & Description \\
\hline & $\begin{array}{l}\text { Number of customers } \\
\text { complain in the system }\end{array}$ & 5 & 1 & \multirow{2}{*}{$\begin{array}{c}\text { The number of complaint } \\
\text { cases decreased }\end{array}$} \\
\hline & $\begin{array}{l}\text { Number of customers } \\
\text { complain in the queue }\end{array}$ & 4.17 & 0.15 & \\
\hline $\begin{array}{l}\text { Classification and } \\
\text { Assignment }\end{array}$ & E.T. & $2 \mathrm{~h}$ & $1.133 \mathrm{~h}$ & $\begin{array}{l}\text { Less time is required for } \\
\text { managing a case }\end{array}$ \\
\hline Improvement & $\begin{array}{c}\text { Reference for } \\
\text { decision-making }\end{array}$ & $\begin{array}{l}\text { Relation between bus } \\
\text { service improvement and } \\
\text { experience of officials }\end{array}$ & $\begin{array}{c}\text { Focus on improvements } \\
\text { in hot spots of } \\
\text { passenger complaints }\end{array}$ & $\begin{array}{c}\text { Bus services are } \\
\text { improved, while } \\
\text { effectively using resources }\end{array}$ \\
\hline
\end{tabular}

\section{Number of Complaints after the Process Improvements}

To verify the effectiveness of the proposed improvement strategies for the customer complaint process, an actual statistical analysis was conducted for three types of cases that most seriously affected passengers' objective perception and were likely to cause discontent. These three types included:

Driving slowly: When a bus runs at idle speed, its passengers feel time pressure and anxiety. Due to its large size, an idling bus seriously impedes traffic, causing danger to other road users.

Station-skipping: A bus may not stop at the designated place, thus, preventing passengers from boarding it.

Unauthorized detours: Bus companies may not fully execute their responsibilities by changing routes without permission. As a result, passengers wait for the bus in vain, which reduces their satisfaction with bus services.

In April 2015, public sector of Taichung City officially began using a systematized approach to analyze big data related to passenger complaints and improve their processing. This study tracked the complaint data for a total 11 months, from April 2015 to February 2016, and conducted a statistical analysis of three complaint types, namely, bus idling (driving slowly), station-skipping, and unauthorized detours. Actual statistical results (Table 11 and Figure 7) showed an improvement in terms of the number of complaint cases. 
Table 11. Numbers of complaint cases of three most serious types.

\begin{tabular}{cccc}
\hline & A: Driving Slowly & B: Skip Stations & C: Unauthorized Detours \\
\hline April 2015 & 27 & 163 & 6 \\
May 2015 & 38 & 162 & 5 \\
June 2015 & 17 & 145 & 12 \\
July 2015 & 26 & 151 & 16 \\
August 2015 & 34 & 134 & 5 \\
September 2015 & 23 & 127 & 12 \\
October 2015 & 18 & 123 & 13 \\
November 2015 & 8 & 111 & 5 \\
December 2015 & 7 & 111 & 1 \\
January 2016 & 2 & 103 & 3 \\
February 2016 & 5 & 105 & 4 \\
SLOPE & -3.05 & -6.54 & -0.59 \\
\hline
\end{tabular}

Except text mining, the intelligent assistant function is also supplied by mining the historical data. It is a statistics result based on the achieved station character to intuitive display the place where events high occurs. The different violate samples was also achieved by each month, through analyzing the characteristics of all violations, the government policy makers and enterprises was able to adjust their focus of work and optimized the allocation of human resources timely. All violation samples are collected from April 2015 to February 2016, and, after the system was put online in October 2015, the optimized results could be obviously observed from the table.

Statistical analysis of the data from 11 months (Figure 7) showed slopes in numbers of complaint cases of each type. A negative slope indicates a decrease in the numbers of complaint cases, with a higher negative value indicating a larger decrease. With regard to the three violation types, the largest reduction in the number of complaint cases after the process improvements was observed in case of station-skipping complaints, followed by bus idling (driving slowly) and unauthorized detours. Good results were observed in all three cases, indicating the effectiveness of complaint process improvement in public sector.

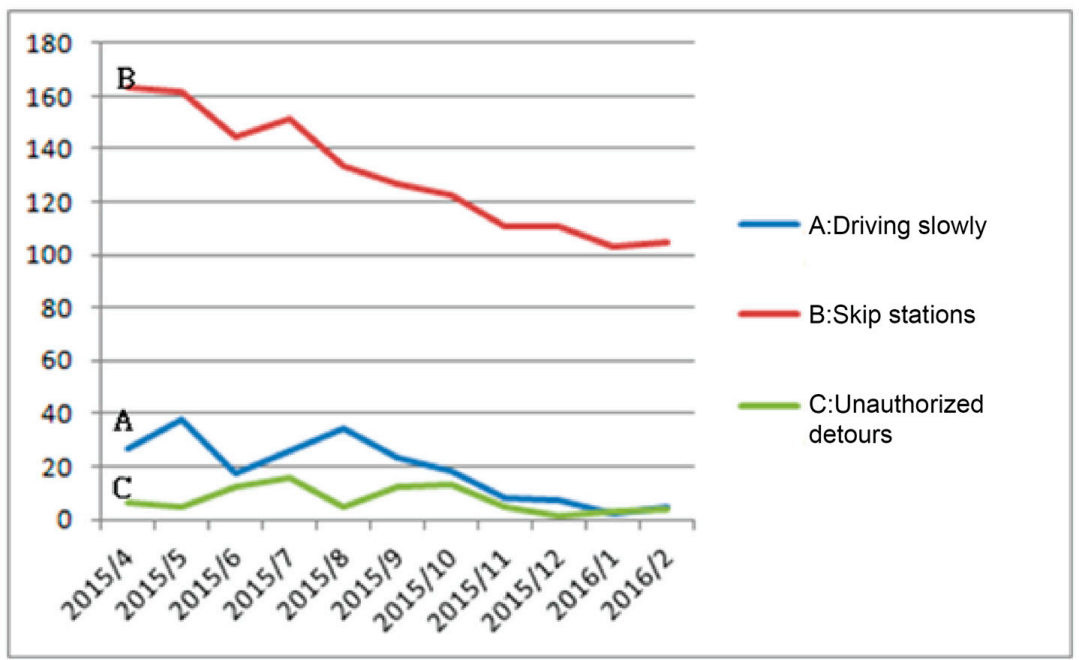

Figure 7. Numbers of complaint cases of three most serious types.

\section{Conclusions}

The use of the process improvements proposed in this study allowed public sector to effectively and promptly assign and process complaint cases. Being more aware of passenger needs, public sector can plan better policies to meet them. Fulfillment of passenger needs can increase the number of 
passengers and, consequently, revenues of bus companies, which, in turn, help improve bus software (services) and hardware (vehicle). Customer satisfaction grows, reducing the number of complaints and establishing a virtuous circle. In other words, a systematized analysis of customer complaint data can improve public sector management processes by improving services through the solution of derived issues. Furthermore, bus services can be improved by strengthening improvements and actively conducting examinations in hot spots of customer complaints. This establishes a virtuous circle in supply chain relationships among public sector, bus companies, and passengers (Figure 8).

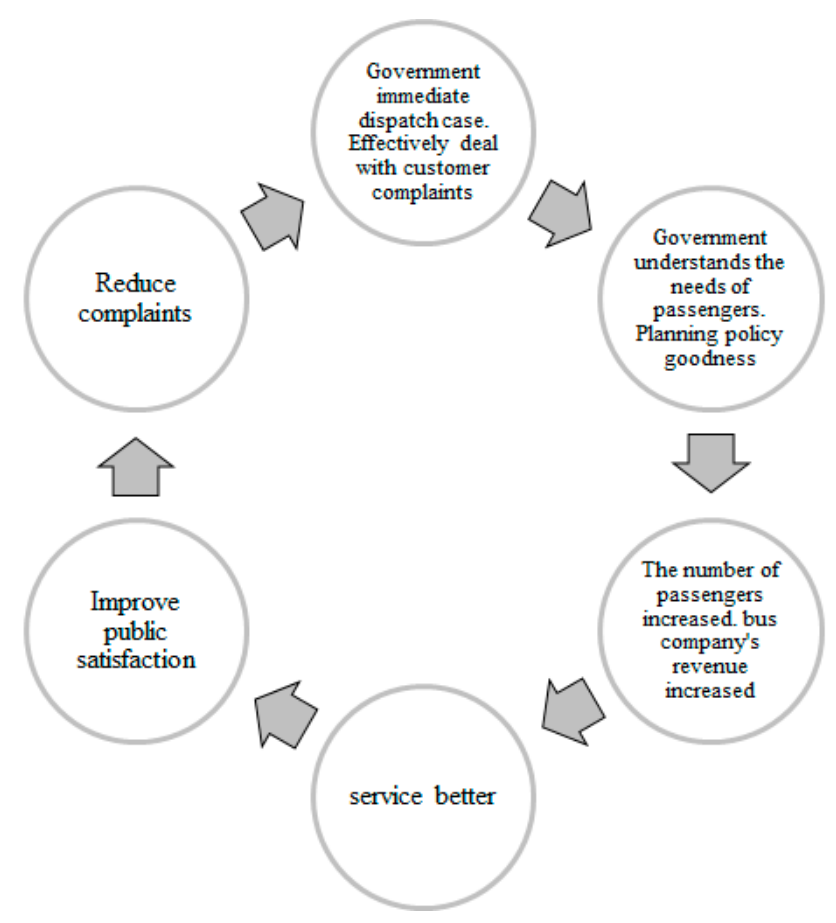

Figure 8. Virtuous circle in the supply chain relationship among public sector, bus companies, and passengers after the complaint process improvements.

Using big data analysis technologies to determine service deficiencies allows improving the overall quality of bus services, while effectively using limited resources, and helps to provide prompt responses to complainants, thus, increasing passenger satisfaction, reducing the number of complaints, and improving the supply chain relationship between public sector, bus companies, and passengers.

Using the example of Taichung City bus services, this study proposed the use of big data analysis technology including systematized case assignment and data visualization to improve management processes in the public sector and optimize customer complaint services. Application of a systematized method in the management of all complaint data regarding Taichung bus services allows statistically deriving hot spots of customer complaints. Thus, bus companies can be aware of what needs to be improved as early as possible and can strengthen improvements in hot spots of passenger complaints. Governmental institutions can prioritize management decisions on the basis of this important information. With regard to the three violation types, the largest reduction in the number of complaint cases after the process improvements was observed in the case of station-skipping complaints, followed by bus idling (driving slowly) and unauthorized detours. The application of the complaint process improvements proposed in this study allowed public sector to effectively process complaint cases and efficiently supervise bus companies. This study showed that the customer complaint process improvements reduced time required for complaint management and the number of complaint cases in public sector. The process improvements allowed effectively using resources, improve the quality of bus services, increase customer satisfaction and increase the number of public transportation system users. Moreover, application of the electronic system to assign complaint cases 
saves the process time and reduces the paper waste between the public sector and bus companies. Reduction of the resource consumption would enhance the effectiveness of environmental protection, thus contributing to energy saving, carbon reduction, and sustainable environmental development of the city. Though the big data analysis technologies are applied in the complaint process, the public sector has to cooperate with bus companies to implement the improvement process. In the beginning, the bus companies are reluctant to change the existing process situation. However, the public sector has to persuade bus companies to execute the complaint improvement process with patience. The public sector has to face huge challenge by implementing the complaint improvement process. The development of the public sector transportation system could be improved by the complaint improvement process which could lead to sustainable environment protection and better life quality.

Acknowledgments: No funding was received for this research. The research data were supported by Transportation Bureau of Taichung City Government, Taiwan.

Author Contributions: The two authors contributed substantially to this research. Weng-Kun Liu conceived and designed the experiments. Chia-Chun Yen collected the materials and analyzed the data. Both Weng-Kun Liu and Chia-Chun Yen performed the experiments and wrote the paper.

Conflicts of Interest: The authors, Weng-Kun Liu and Chia-Chun Yen declare no conflict of interest in this study.

\section{References}

1. Cooper, T.L.; Bryer, T.A.; Meek, J.W. Citizen-Centered Collaborative Public Management. Public Adm. Rev. 2006, 66, 76-88. [CrossRef]

2. Aikins, S.K.; Krane, D. Are Public Officials Obstacles to Citizen-Centered E-Government? An Examination of Municipal Administrators' Motivations and Actions. State Local Gov. Rev. 2010, 42, 87-103. [CrossRef]

3. Berry, J.M.; Thomson, K.; Portney, K. The Rebirth of Urban Democracy; Brookings Institution Press: Washington, DC, USA, 1993.

4. Eaton, C.; Deroos, D.; Deutsch, T.; Lapis, G.; Zikopoulos, P. Understanding Big Data: Analytics for Enterprise Class Hadoop and Streaming Data; McGraw-Hill Press: New York, NY, USA, 2012.

5. Wright, L.; Fulton, L. Climate Change Mitigation and Transport in Developing Nations. Transp. Rev. 2005, 25, 691-718. [CrossRef]

6. Barter, P.A.; Dotson, E. Urban Transport Institutions and Governance and Integrated Land Use and Transport, Singapore. Available online: http://unhabitat.org/wp-content/uploads/2013/06/GRHS.2013. Case_.Study_.Singapore.pdf (accessed on 10 August 2016).

7. Pucher, J.; Park, H.; Kim, M.H.; Song, J. Public Transport Reforms in Seoul: Innovations Motivated by Funding Crisis. J. Public Transp. 2005, 8, 41-62. [CrossRef]

8. Barter, P.A. Singapore's Urban Transport: Sustainability by Design or Necessity? In Spatial Planning for a Sustainable Singapore; Wong, C., Yuen, B., Goldblum, C., Eds.; Springer: Dordrecht, The Netherlands, 2008; pp. 95-112.

9. Liao, C.P.; Chen, D.Y.; Hsiao, N.Y.; Liao, H.Z. Using Big Data to Achieve Good Governance: A Feasibility Study on Introducing Cyber Opinion into Government Decision-Making Process; Research, Development and Evaluation Commission, Executive Yuan: Taipei, Taiwan, 2014.

10. Jin, Y.; Ji, S. Partner Choice of Supply Chain Based on 3D Printing and Big Data. Inf. Technol. J. 2013, 12, 6822-6826. [CrossRef]

11. Coussement, K.; Poel, D.V.D. Improving Customer Complaint Management by Automatic Email Classification Using Linguistic Style Features as Predictors. Decis. Support Syst. 2008, 44, 870-882. [CrossRef]

12. Zhang, K.; Narayanan, R.; Choudhary, A. Voice of the Customers: Mining Online Customer Reviews for Product Feature-based Ranking. WOSN 2010, 10, 11.

13. Ziegler, C.N.; Skubacz, M.; Viermetz, M. Mining and Exploring Unstructured Customer Feedback Data Using Language Models and Treemap Visualizations. In WI-IAT '08 Proceedings of the 2008 IEEE/WIC/ACM International Conference on Web Intelligence and Intelligent Agent Technology-Volume 01; Ziegler, C.N., Skubacz, M., Viermetz, M., Eds.; IEEE Computer Society: Washington, DC, USA, 2008; pp. 932-937. 
14. Zhang, L.; Liu, B.; Lim, S.H.; O’Brien-Strain, E. Extracting and Ranking Product Features in Opinion Documents. In Cooling 2010: Poster Volume; Huang, C.R., Jurafsky, D., Eds.; Tsinghua University Press: Beijing, China, 2010; pp. 1462-1470.

15. Tai, C.Y. The Policy Effect of One-Stop Service on Internal Customer: A Case Study of Taipei's 1999 Citizen Hotline Service. Master's Thesis, Tamkang University, Taipei, Taiwan, 2014, unpublished.

16. Yan, C.C. Taichung City Bus Operation Decision Analysis and Management System Implementation Plan: Taichung City Transportation Bureau Mid-Term Report; Hung Ming Information Co.: Taichung, Taiwan, 2014.

17. Yang, H.P. Using Value Analysis in Business Processes. Value Manag. 2003, 5, $43-47$.

18. Davenport, H.T.; Sbort, J.E. The New Industrial Engineering: Information Technology and Business Process Redesign. Sloan Manag. Rev. 1990, 31, 11-26.

19. Gates, B. Business @ the Speed of Thought: Succeeding in the Digital Economy; Grand Central Publishing: New York, NY, USA, 1999.

20. Adesola, S.; Baines, T. Developing and evaluating a methodology for business process improvement. Bus. Process Manag. J. 2005, 11, 37-46. [CrossRef]

21. Gunasekaran, A.; Nath, B. The role of information technology in business process reengineering. Int. J. Prod. Econ. 1997, 50, 91-104. [CrossRef]

22. O’Neill, P.; Sohal, A.S. Business Process Reengineering A review of recent literature. Technovation 1999, 19, 571-581. [CrossRef]

23. Attaran, M. Exploring the relationship between information technology and business process reengineering. Inf. Manag. 2004, 41, 585-596. [CrossRef]

24. Love, P.E.D.; Gunasekaran, A. Process reengineering: A review of enablers. Int. J. Prod. Econ. 1997, 50, 183-197. [CrossRef]

25. Sullivan, D. Document Warehousing and Text Mining: Techniques for Improving Business Operations, Marketing, and Sales; John Wiley \& Sons, Inc.: New York, NY, USA, 2001.

26. Ordenes, F.V.; Theodoulidis, B.; Burton, J.; Gruber, T.; Zaki, M. Analyzing Customer Experience Feedback Using Text Mining: A Linguistics-Based Approach. J. Serv. 2014, 17, 278-295. [CrossRef]

27. Wilkinson, L.; Fridnely, M. The History of the Cluster Heat Map. Am. Stat. 2009, 63, 179-184. [CrossRef]

(C) 2016 by the authors; licensee MDPI, Basel, Switzerland. This article is an open access article distributed under the terms and conditions of the Creative Commons Attribution (CC-BY) license (http://creativecommons.org/licenses/by/4.0/). 